This PDF is a selection from a published volume from the National Bureau of Economic Research

Volume Title: Social Security Programs and Retirement around the World: Historical Trends in Mortality and Health, Employment, and Disability Insurance Participation and Reforms

Volume Author/Editor: David A. Wise, editor

Volume Publisher: University of Chicago Press

Volume ISBN: 0-226-90309-5; 978-0-226-90309-5

Volume URL: http://www.nber.org/books/wise11-1

Conference Date:

Publication Date: September 2012

Chapter Title: Disability in Belgium: There Is More Than Meets the Eye

Chapter Author(s): Alain Jousten, Mathieu Lefebvre, Sergio Perelman

Chapter URL: http://www.nber.org/chapters/c12387

Chapter pages in book: (p. 251 - 276) 


\title{
Disability in Belgium There Is More Than Meets the Eye
}

\author{
Alain Jousten, Mathieu Lefebvre, and Sergio Perelman
}

\subsection{Introduction}

The economic literature has produced a wide body of research on the determinants of labor supply at older ages. It suggests that the generous early retirement routes opened up within the setting of various social protection systems are largely responsible for the low participation of elderly. There is no doubt that the strongest factors driving early retirement are the financial incentives provided by social security systems, but health issues might be of importance as well. ${ }^{1}$

Specifically, disability insurance (DI) is a key component of the social security system in most advanced countries. Belgium is no exception to this role with the public DI system protecting workers in case of longer-term loss of work capacity. However, few studies on Belgium have focused on DI as one of several systems allowing elderly to leave the labor force.

As compared to the substantially larger health and retirement programs, DI has only attracted a limited interest in the Belgian public policy debate.

Alain Jousten is professor of economics at the University of Liège and a research fellow with the Institute for the Study of Labor (IZA) and with Netspar. Mathieu Lefebvre is a postdoctoral researcher at the University of Liège. Sergio Perelman is professor of economics at the University of Liège.

The authors wish to thank Michael Turco (CIMIRE), Lut Vanden Meersch (INAMIRIZIV), and Khiêm Nguyen (ONEM-RVA). Financial support from the Communauté Française de Belgique ARC contract (ARC 05/10-332) is gratefully acknowledged. All errors are our own. For acknowledgments, sources of research support, and disclosure of the authors' material financial relationships, if any, please see http://www.nber.org/chapters/c12387.ack.

1. See Pestieau and Stijns (1999); Dellis et al. (2003); Desmet et al. (2007); Disney, Emmerson, and Wakefield (2006); and Kalwij and Vermeulen (2008). 
According to Eurostat, spending on DI accounted for only 1.8 percent of gross domestic product (GDP) in 2007. Two key factors are at play.

On the one hand, while there is no doubt that poor health is a key determinant of inactivity, the multiplicity of exit routes available to older workers in Belgium makes it difficult to clearly identify the relationship between health condition and DI participation and, hence, also the influence of DI on retirement decisions. On the other hand, poor health may also affect a worker's productivity and, hence, affect his or her risk of job loss. In both cases, there exist various schemes that allow the workers to withdraw from the labor market.

In light of these issues, we focus on two specific questions in this chapter. First, we evaluate whether there is a systematic link between indicators of population health - both objective and subjective - and program participation. We research whether the improvement observed in health status and mortality in the last decades is associated with a reduction of programs participation - with a special focus on the DI program. We would expect such a link to prevail, though causality of this link could obviously run both ways.

Second, we describe the role of the DI system in the wider social security system. Previous work on retirement incentives has clearly illustrated the need to take a comprehensive approach when looking at the behavioral consequences of social protection systems - particularly in a context of reform over time (see Dellis et al. 2004, Desmet et al. 2007). Indeed, Belgium excels in the use of a variety of early retirement programs if the average age of retirement was about 61.4 in 2007; it was 57 in 2000.

The chapter is structured as follows. Section 6.2 describes the institutional landscape of the Belgian social insurance and assistance schemes. We provide a description of the changes to the different early retirement schemes over time-with an emphasis on those relevant in the disability context. Section 6.3 provides an overview of historical data on health trends. Relying both on administrative and survey data, we show the link between health status and mortality trends, on the one side, and labor market and disability participation, on the other. Section 6.4 analyzes program participation, with a special emphasis on the link between behavioral trends and changes in the program design. This is of prime importance because the coexistence of several schemes raises a problem of communicating vessels, wherein a change in the rules of one scheme may have a direct impact on the participation to another scheme. Section 6.5 concludes the chapter.

\subsection{Institutional Background}

The aim of this section is to describe the most important social protection schemes that can serve as a source of replacement income when retiring from the labor market within a disability context. As in previous work on retirement incentives and labor market outcomes (see Jousten et al. 2005, 2010), 


\begin{tabular}{lll}
\hline DI & Disability insurance system \\
UI & Unemployment insurance system \\
CER & Conventional early retirement system \\
SER & Special early retirement system \\
RPP & Retirement prepension system \\
OAU & Old-age unemployment system \\
\hline
\end{tabular}

for reasons of data availability, our focus will be the wage-earner scheme. ${ }^{2}$ (See table 6.1.)

\subsubsection{Disability Insurance (DI)}

The DI system is the main program targeted at people withdrawing from the labor market for disability reasons. To be eligible for the benefit, the worker has to satisfy a series of conditions. First, there is a condition in terms of the loss of earnings capacity in the usual job. In order to be eligible, the worker has to suffer from a loss of earnings capacity of 66 percent over a period of at least twelve months - as certified by the national DI administration (INAMI-RIZIV). Continued benefit eligibility is validated using periodic medical and administrative controls.

Beyond this loss of earnings-capacity requirement, workers also have to satisfy minimum contributory requirements to qualify for benefits. The coverage under the system prior to the onset of the disability has to be assured for at least two quarters, combined with at least 120 days of actual or assimilated work (or 400 hours for part-time workers) before the covered event occurs. The system is financed on a pure pay-as-you-go (PAYG) basis.

Benefits are payable up to a maximum age of sixty-five - corresponding to the normal retirement age. At this age, people become eligible for regular retirement benefits and are automatically transferred into the retirement system. In line with other social insurance replacement income programs, such as unemployment insurance (UI), health insurance (HI), and conventional early retirement (CER), periods of benefit receipt fully count toward the buildup of pensions - though no contributions are due. Periods on DI are fully assimilated to work in pension records, with fictive (indexed) wages being imputed into the earnings history at a level corresponding to real earnings in the year prior to disability onset (see the following).

The benefit level is a function of the household status of the worker and is paid out free of income taxes. The benefit is equal to 65 percent of reference earnings if the insured has dependents, 40 percent if the insured cohabits

2. The wage earner social insurance system is by the far the largest one in terms of enrollment terms, also representing the largest share of public spending on social security. It is less generous than the scheme for civil servants and more generous than the one for the self-employed. 
but has no dependents, and 53 percent if the insured lives alone. Reference earnings are based on real observed earnings in the period leading up to the onset of the insured event. A cap on benefits applies for higher levels of income. Benefits are adjusted periodically for changes in the consumer prices using the so-called health-index - a slowed-down version of the Consumer Price Index (CPI) serving as a basis of indexation notably for rents and social benefits.

In the twelve months leading up to the benefit eligibility, workers suffering from a loss of work capacity are not left without income. During this socalled primary incapacity, people are covered under the rules of the HIwith slightly different eligibility rules that are administered in a decentralized way by the various mutual health insurance organizations. During the first month of incapacity, the benefit is equal to 60 percent of the reference income. Over the next eleven months, the benefit is equal to 60 percent if the insured has dependents or lives alone and 55 percent if he or she cohabits.

When the DI system was introduced in 1963, the benefit was equivalent to 60 percent of reference earnings if the insured has dependents and 33 percent otherwise. These replacement rates were adjusted along time. In 1986, a differentiation between individuals living alone and cohabitants was introduced and replacement rates adjusted to 65 percent for insured with dependents, 40 percent if cohabiting with no dependents, and 45 percent if the disabled person lives alone. In 2002, the replacement rate of the disabled living alone was further increased to 50 percent before finally reaching current levels in 2004.

Aside from changes in the replacement rates, an important reform occurred in 1998, significantly enlarging the notion of "dependents" by including the members of the spouse's family. The aim was to align the definition with the one used in the unemployment rules in order to make systems more coherent.

\subsubsection{Pension System}

The wage-earner pension system is the main program covering the elderly. The program is financed by tax-deductible employer and employee contributions as well as by transfers from the federal budget. The system runs on a pure PAYG basis.

Individuals are eligible to full benefits at the age of sixty-five, with early retirement possible at age sixty for both women and men. A full career corresponds to forty-five years of earnings or assimilated periods. Assimilated periods correspond to periods on DI, UI, HI, CER, as well as various other arrangements such as career breaks and some other forms of leave. No actuarial adjustment is applied for early retirement beyond the effect possibly playing through the incompleteness of the earnings history.

Social security benefits correspond to 75 percent of average lifetime earnings for one-earner couples and to 60 percent for others. Benefits have a 
preferential tax treatment and are regularly indexed using the health index as well as occasionally uprated on a purely discretionary basis to prevent a severe decoupling of benefits from average wages in the economy. Special regimes also remain in place for some specific sectors, such as most notably for coal mining and the maritime sector. Survivor benefits are available since 1968.

Originally, the basis for the current-day system was laid in two separate steps for blue- and white-collar employees in 1953 and 1957. Since its creation, the system has undergone a series of major changes. In 1967, the systems were merged and key changes introduced. Male retirement age was set at sixty-five and female retirement at sixty, with corresponding full-career lengths of forty-five and forty years - combined with a possibility to retire early by five years with a 5 percent reduction per year of anticipation.

A reform of 1977 can be seen as the first step toward an active policy of shifting people into inactive early retirement program - even though this specific program was only short-lived and phased out in 1979 and $1982 .{ }^{3}$ The reform allows for early retirement within the preceding general pension system without financial penalties. The so-called special early retirement (SER) gives disabled workers or long-term unemployed aged of at least sixty for men and of fifty-five for women a bonus equal to the difference between the actual pension and the one they would receive if it was not reduced by the 5 percent rule.

The ensuing 1983 creates a new (and longer-lived) scheme of early retirement within the framework of the wage-earner pension system. The program of retirement prepension (RPP) allows male workers to retire a maximum of five years early without any benefit reduction if the employer commits to replacing the worker by an unemployed who is benefiting from a full-time compensation from the unemployment insurance. The system only ended in 1991 with the formal end of a normal retirement age.

In 1991, a major reform of the system modifies the landscape in retirement ages. While female early retirement before the age of sixty was already eliminated in 1987, the 1991 reform generalized the concept of a window of retirement ages: subject to career requirements, workers of both sexes are free to choose the retirement age between sixty and sixty-five. The normal retirement ages for women and men do, however, remain different at ages sixty and sixty-five. The 5 percent rule as well as the RPP both lose their rationale and are eliminated.

It is, however, only in 1997 that the Belgian government, forced by a European court of justice ruling, harmonized the normal retirement age and the career-length requirements for women and men. The decision was taken to

3. The program was the first of a series of programs put in place to shift older workers out of the labor market to free up jobs for younger workers. E.g., Walker (2007) and Jousten et al. (2010) discuss these "lump-of-labor" issues in more detail and with diverging conclusions. 
align the female full career condition to the one applicable to men. Since 1997, the normal retirement age for women has gradually been raised to sixty-one in 1997, sixty-two in 2000, sixty-three in 2003, sixty-four in 2006, and, finally, attained the now steady-steady of sixty-five in 2009, with the corresponding increases in full-career requirements. While aimed at eliminating discrimination, the measure has also a clearly beneficial impact in budgetary terms and contributes positively to the longer-term viability of the regime.

The most recent reform to retirement incentives under the pension system dates back to 2007. Under the so-called Intergenerational Solidarity Pact (ISP) negotiated between the social partners and the government in late 2005 , workers working beyond the age of sixty-two or beyond forty-four years of career can benefit from a pension supplement. ${ }^{4}$ The pension bonus of an amount of $€ 2$ per day worked beyond these limits, augments the annual benefit payable, and this independently of the wage earned or the contributions accumulated. As such, it can be seen as a much stronger relative incentive for lower-wage earners than for higher-wage earners.

\subsubsection{Conventional Early Retirement}

Next to the pension system, a parallel system of complementary benefits for early retirement is created in 1973 for the old workers in case of firing: the conventional early retirement (CER). In order to be eligible, the worker has to have been laid off by his or her employer and also satisfy some career length requirements. ${ }^{5}$ Benefits correspond to the ones payable under the unemployment insurance system (see the following) topped up by a complementary benefit paid by the employer - the latter being equal to half the difference between net wage and the unemployment benefit.

A particularity of the system is that these early retirees are exempted from job search and - as for all unemployed - the time spent in the early retirement program is fully credited in the earnings file for pension purposes.

At the outset, the system is only accessible if the employer recruits a replacement worker benefiting from full-time unemployment benefits as a replacement for the worker.

Further, the initial age of eligibility is set at sixty. But both criteria are hollowed out over time by means of legislative change and collective bargaining agreements within industries. As a result, there ultimately exists a variety of different regimes with different career requirements, minimum ages, re-

4. The Belgian Intergenerational Solidarity Pact includes some thirty measures aimed at reducing early retirement without changing the legal retirement age or current benefits already granted. Measures include limiting the number of people taking early retirement, stimulating employers to retain or hire older workers, as well as making early retirement less attractive for both workers and employers.

5. Initially, the minimum length was set to twenty-five years. It has been gradually increased to thirty years for men and twenty-six years for women. In 2012, it it set to increase to thirtyfive and twenty-eight years for men and women, respectively. 
placement of the worker, and so on for different sectors and companies. Though legislation from 1986 as well as the ISP of 2005 tried to harmonize and put constraints onto this situation, numerous exceptions persist with respect to the general rules. Even today, while workers below the age of sixty do in theory have to be replaced when they are put onto early retirement, this is not the case for companies that are considered in economic difficulty or in restructuring - with the age sometimes being as low as fifty. The same applies if the company is closing or unable to find a suitable replacement and so on. Similarly, while the age of fifty-eight is currently the statutory minimum access age, a lower age is possible in some sectors (steel, glass, textile, etc.) depending on more stringent career conditions or conditions on hardship of the job.

\subsubsection{Unemployment and Old-Age Unemployment}

The last exit path out of the labor market works through the unemployment insurance system. Two alternatives exist, the specific old-age unemployment (OAU) system and the regular UI system.

Eligibility for the regular UI system is essentially based on having paid contributions during at least twelve months in paid employment or assimilated periods in the last eighteen months. The basic UI system is available to workers of all ages and pays out benefits of 60 percent of the last gross wage. Both the reference wage and the benefits have caps and floors. As a result, the replacement rate of the unemployment benefits was 30 percent of average gross wages in 2004 (Faniel 2008). Benefits are not subject to income tax and are not limited in time with payments ending upon reaching the normal retirement age of sixty-five. At this age, the transit into the pension system follows rules similar to the DI system.

Under UI rules, individuals have to be available for the job market and actively look for employment. A specificity of the system is that benefits, as for the rest of social security, are paid out by a federal agency, while job placement is only in the hands of the various regional authorities.

The OAU status was introduced back in 1985 into the Belgian social insurance landscape. In line with the previously discussed programs, its motivation was essentially one of freeing up space on the job market in a lump-of-labor logic (see Jousten et al. 2010). As compared to the regular UI system, several key factors of differentiation exist. First, the beneficiary of OAU benefits does not have to be actively looking for a job, nor does he or she have to be available for the labor market. Second, benefits are more generous than UI. In addition to the UI benefits, the old-age unemployed receive a complement that is a function of age and family status.

To qualify for OAU, workers have to satisfy age and unemployment criteria. Initially, the system was limited to those people aged fifty-five and above who were unemployed for at least two years; as of 1996 the age was lowered to fifty and the UI duration to one year. In 2004, faced with the 
growing importance of these arrangements, the government progressively introduced changes to the legislation. New entrants currently have to satisfy more stringent conditions to benefit from the job search and availability waiver. Under the new rules, only workers aged fifty-eight and above or with long careers still benefit from a full waiver, younger workers benefiting from an intermediate system as compared to the basic UI system. ${ }^{6}$

In its most extreme version, the system has been used in what is known as Canada Dry retirement arrangements (Cremer, Lozachmeur, and Pestieau 2009), where employers separate from older workers by sweetening the firing with lump-sum compensations or side payments - this way avoiding the more complicated and stringent severance pay.

\subsection{Historical Health Trends}

After having reviewed the institutional setting, it is useful to review some indicators of outcomes in terms of health and mortality. Figure 6.1 presents the general trend in terms of mortality for the population aged fifty-five to sixty-five in Belgium. While there has been some variation across sexes and age groups, the dominating trend is clearly a steep decrease in mortality or, expressed differently, a steep increase in life expectancy. Though encouraging, it does, however, not mean that morbidity also decreased.

Two additional figures give a snapshot picture of the strong improvements in mortality. The first indicates the age at which members of the age sixty and sixty-five cohorts in the various calendar years will suffer from a mortality rate that their 1960 counterparts suffered when sixty and sixty-five, respectively. The increasing trend displayed in figure 6.2 indicates a clear shift toward longer life expectancies as higher mortality rates occur much later in life, about ten years from 1960 to 2006.

The second compares mortality rate for men and women in 1960 and 2005. Considering a 5 percent mortality rate, figure 6.3 shows that the age at which this rate is attained shifted from sixty-nine to seventy-six for men and from seventy-three to eighty for women, a gain of seven years in both cases.

Beyond pure mortality indicators, we only have very limited health data available. The first one is the Eurobarometer - a cross-national survey carried out over a wide range of European countries. A question on subjective health has been asked periodically for the years 1987, 1989, 1990, 1993, and 2001. However, a major drawback is that the question is not expressed in the same way, and the scale of answers has also changed overtime. The second survey is the Belgian Health Interview Survey (HIS) that exists since 1997

6. Starting in 2002, the age at which people can claim the old-age unemployed status is increased to fifty-eight, with a transitory period in which it is first fifty-six then fifty-seven. To exit the labor market before these ages, the workers have to justify a career of thirty-eight years. 

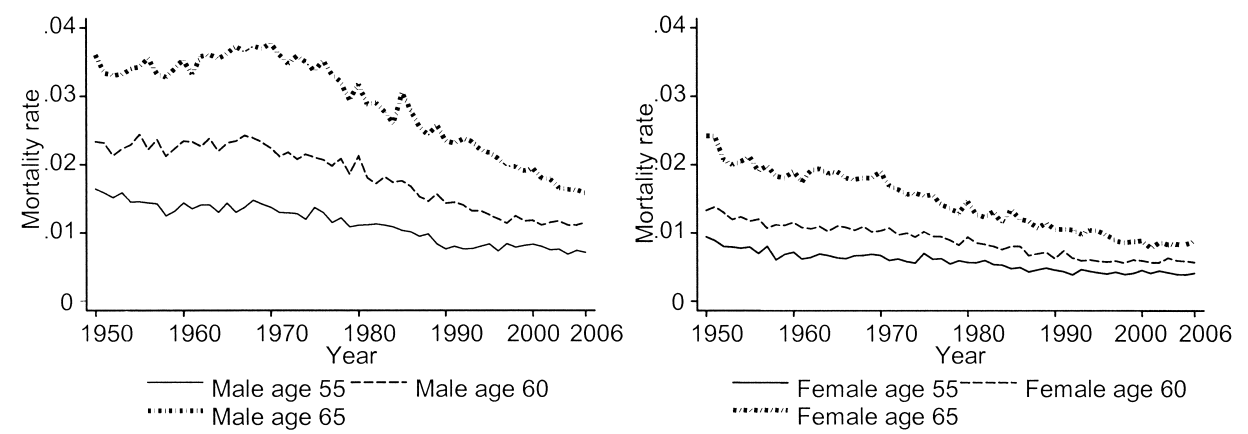

Fig. 6.1 Mortality rates for male (left) and female (right)

Source: Human Mortality Database.

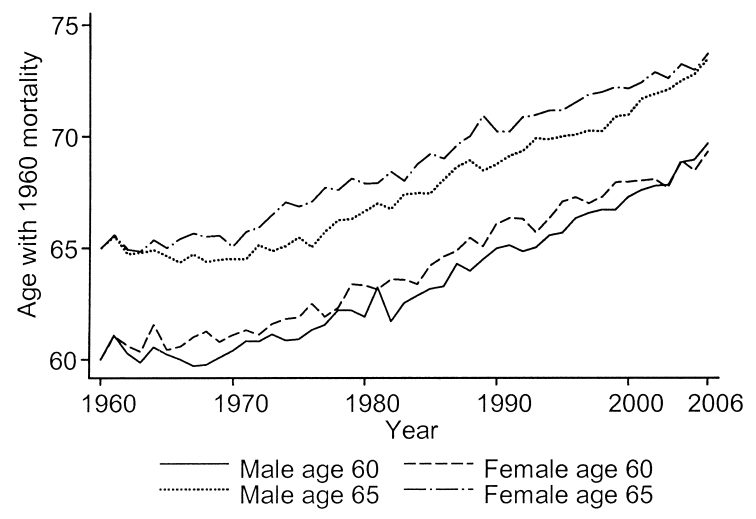

Fig. 6.2 Ages of equal mortality

Source: Human Mortality Database.

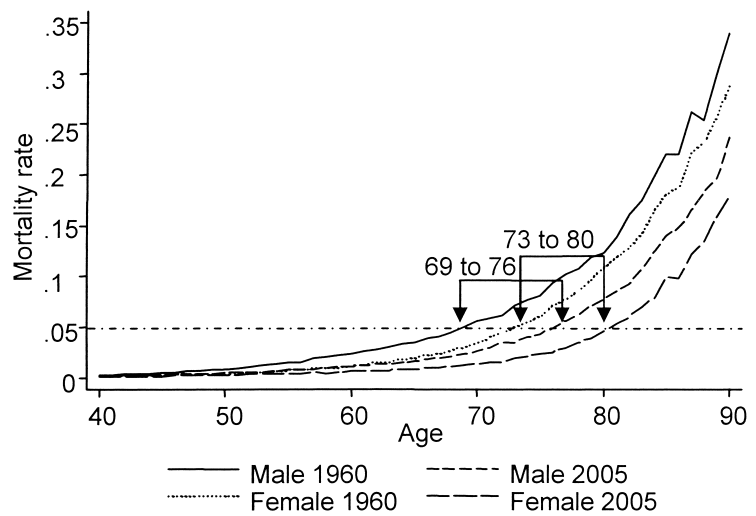

Fig. 6.3 Mortality rates by age

Source: Human Mortality Database. 

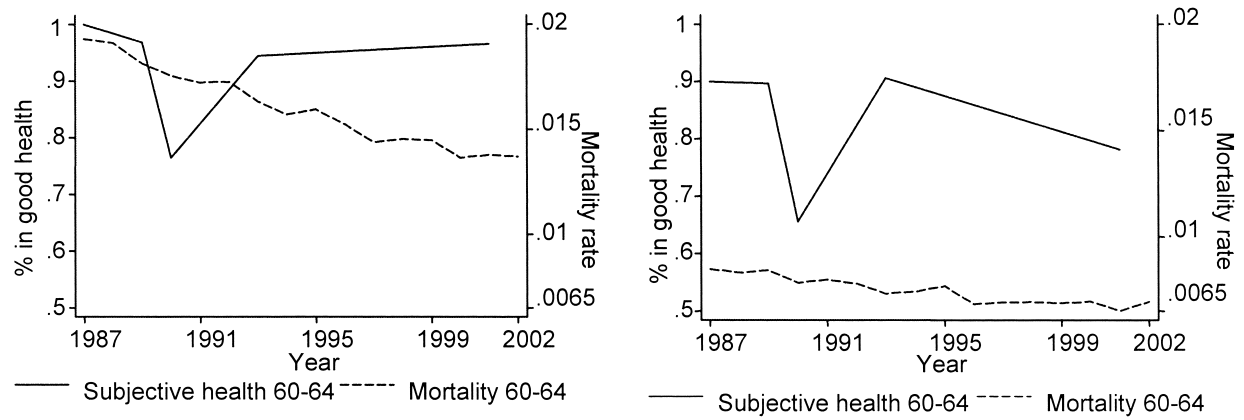

Fig. 6.4 Good health (Eurobarometer) and mortality for male (left) and female (right)

Sources: Eurobarometer and Human Mortality Database.

Note: The subjective health indicator gives the percentage of people who declare to be in fairly good, good, or very good health.

and is conducted every four years. For the latter, we only have access to data by ten-year age cohorts.

Looking first at the Eurobarometer data of figure 6.4 and comparing with the underlying mortality trends also plotted on the graphs, it is clear that this data has only a very limited use - if only because of the changing questions over the different waxes. While the mortality rates show a clear improvement along the period, the perceived health displays no clear pattern.

The HIS provides self-reported subjective and objective health measures. The advantage is that the HIS allows to link mortality to morbidity. Figure 6.5 displays the percentage of people aged fifty-five to sixty-four who declare being in a bad health, those having functional limitations, those having chronic conditions, and the average body mass index in this population. It show that, contrary to the drop in mortality also reported, health measures look rather flat - except maybe for the subjective health measure that seems to display a slightly decreasing trend, especially for women.

Given the sparse information on direct health outcomes, we conclude that mortality is likely the only meaningful indicator of health improvements in Belgium. Also, it is the only available indicator covering a rather long period and showing consistent estimation along time.

To get a sense of the importance of longevity changes on labor force participation, we present cross-tabulations of two key labor force indicators against mortality. Implicitly, we want to verify whether changes in the average health and well-being of the population affect the labor market. In theory, if the DI system were to play its role as a protection against bad health, both variables should be affected - particularly for workers close to the retirement age. Figure 6.6 plots the trends of mortality against the employment rate and DI receipt. The employment rate is derived using the 


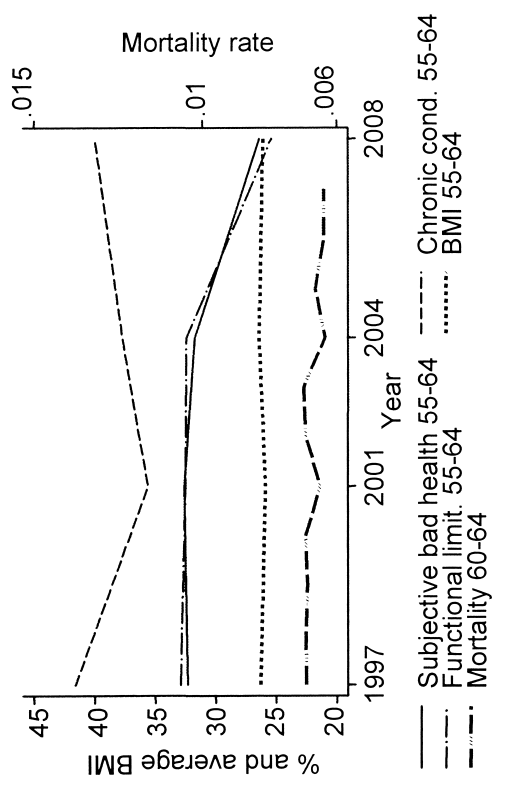

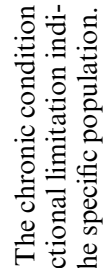

声要

总

宽

के ठ융

귤요



항

范

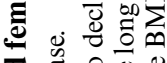


今

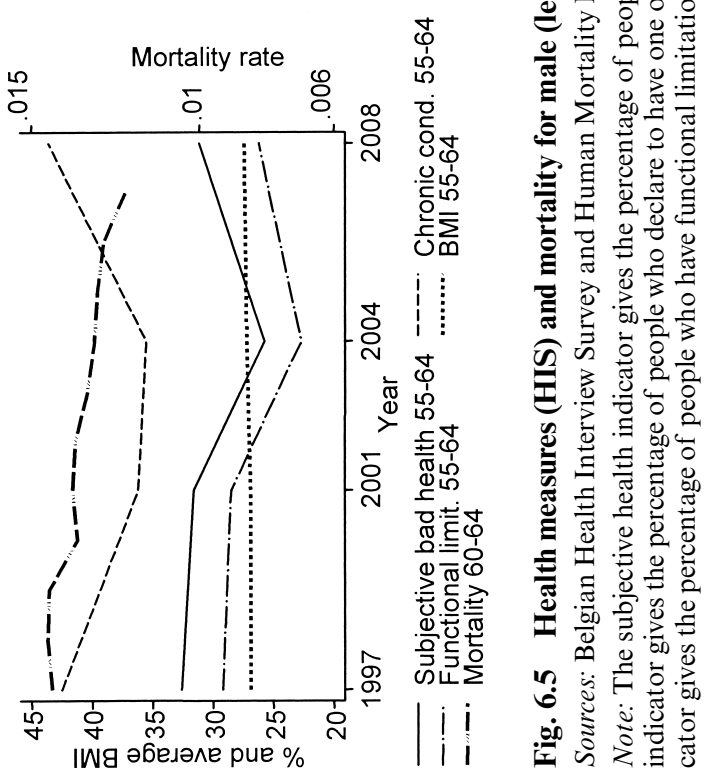




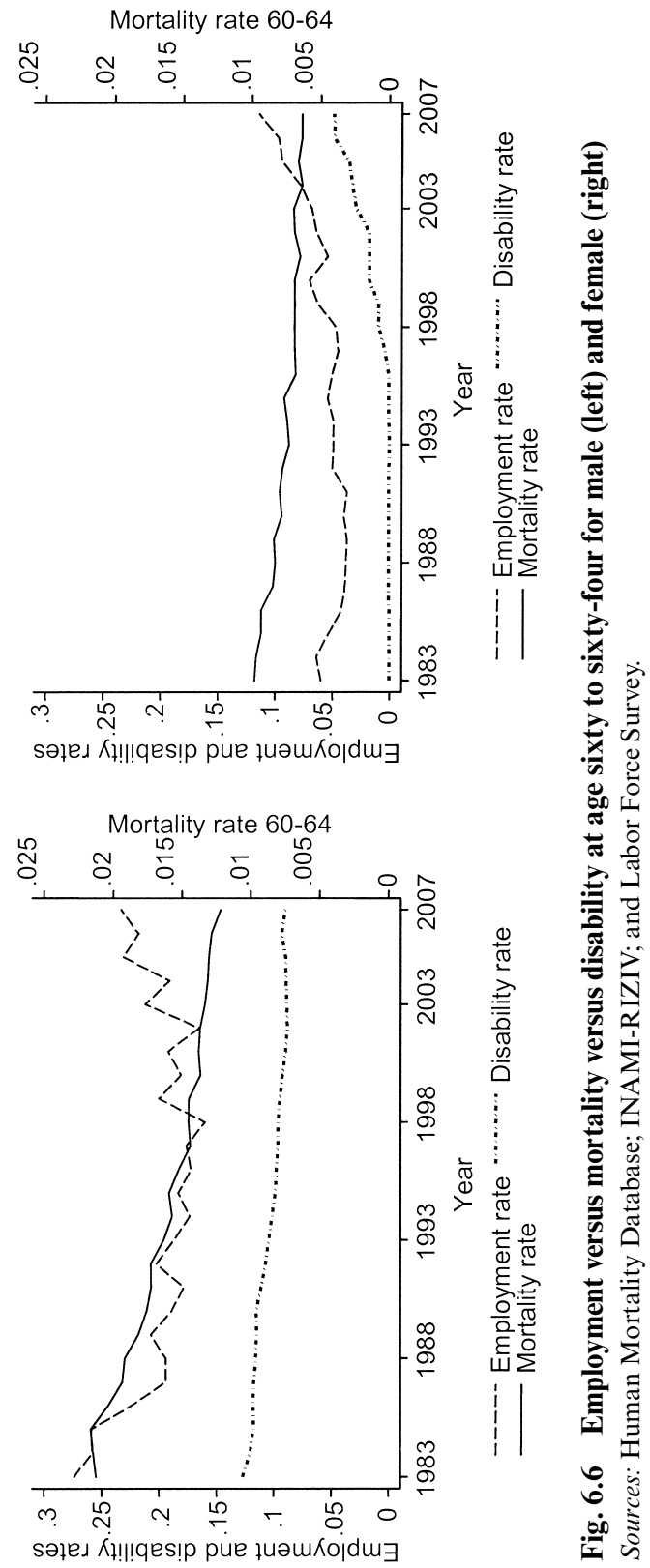


data from the Labor Force Survey that has been conducted since the early 1980s, while the DI rate is based on data from the federal DI administration. ${ }^{7}$

For men, mortality has faced a steady decline over this twenty-five-year period, while the employment rates have started to edge upward since the end of the 1990s - a trend more broadly observed all across the Organization for Economic Cooperation and Development (OECD). The same is true, though to a lesser extent, for DI in the second half of the first decade of the new millennium. For women, the upward trend in employment is much more sustained and can largely be explained by an increasing fraction of women joining the labor market and becoming eligible for benefits. Furthermore, the inexistence of DI recipiency until the late 1990s and the steep increase thereof at the end of the observation period can be explained by the increase of the retirement age from a departure level of sixty - hence originally excluding all women above sixty from the benefits of the DI system.

One conclusion emerges: DI receipt and employment rates do not correlate well with mortality or health indicators.

\subsection{Pathways to Retirement and Program Reform}

This section extends the previous analysis and looks beyond the narrow concept of DI benefit receipt as an indicator of program participation. It also expands the focus beyond the age group sixty to sixty-four as similar effects on activity levels can also affect younger and older cohorts.

\subsubsection{Key Labor Market Indicators}

Figures 6.7, 6.8, and 6.9 give an overview of labor market outcomes over the period of time covered by the Labor Force Survey. These more extensive labor force data comfort the previous observations of long-term trends on the labor market, with male rates being relatively stable over the entire period of observation, while female employment and labor force participation strongly trend upward. While unemployment rates vary considerably over the economic cycle, there is little impact on overall employment and labor force participation levels.

Beyond these traditional sets of labor market indicators, we propose two additional measures. Figure 6.10 graphs the same Labor Force Survey employment data for the ages ranging from fifty to seventy in three different calendar years. It confirms the preceding observations.

A final tabulation links the employment rate to mortality rates in different calendar years. Every point represents the position of a five-year age bracket in the given year. The results of figure 6.11 shows that employment rates at any given mortality rate have steadily dropped for men. The reason for this

7. We rely on administrative data given that Labor Force Survey data on disability are only available for the period starting in 1992 and are rather erratic. 

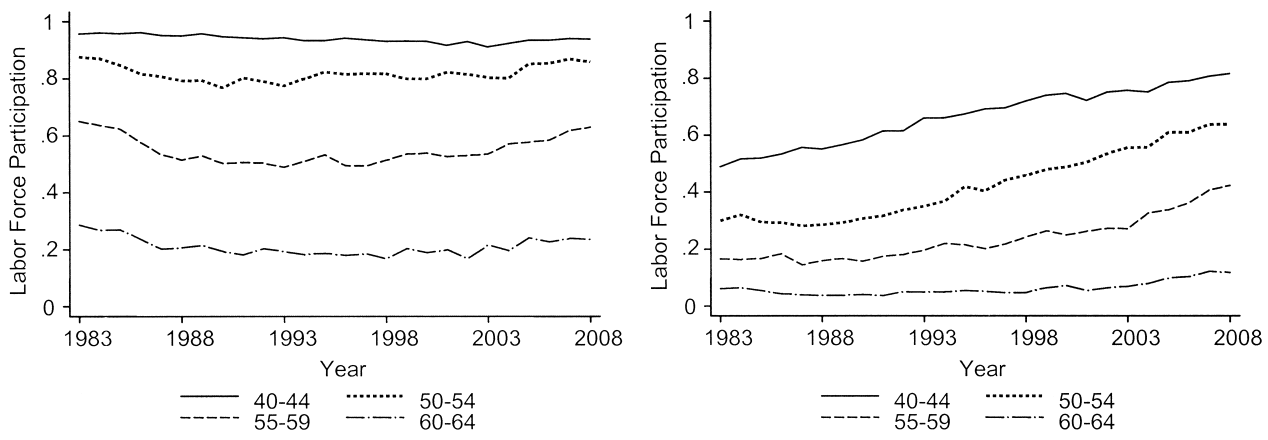

Fig. 6.7 Labor force participation for male (left) and female (right)

Source: Labor Force Survey.
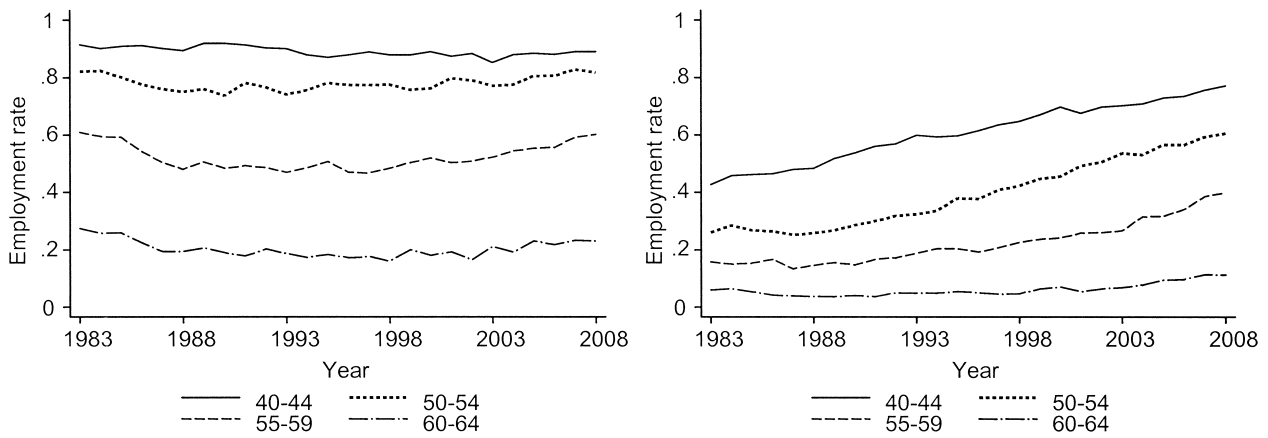

Fig. 6.8 Employment rate for male (left) and female (right)

Source: Labor Force Survey.
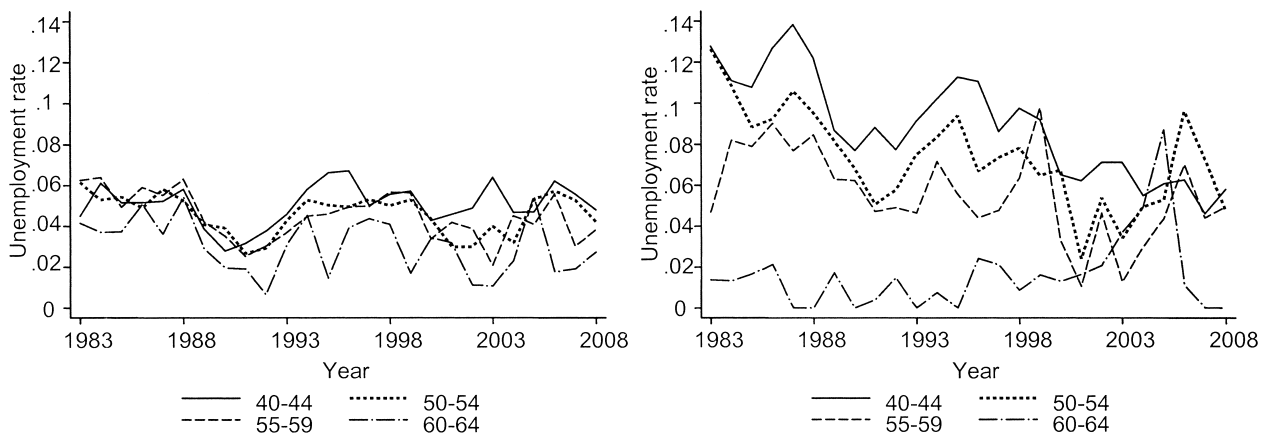

Fig. 6.9 Unemployment rate for male (left) and female (right)

Source: Labor Force Survey. 



Fig. 6.10 Employment rate five-year age bracket for male (left) and female (right) Source: Labor Force Survey.
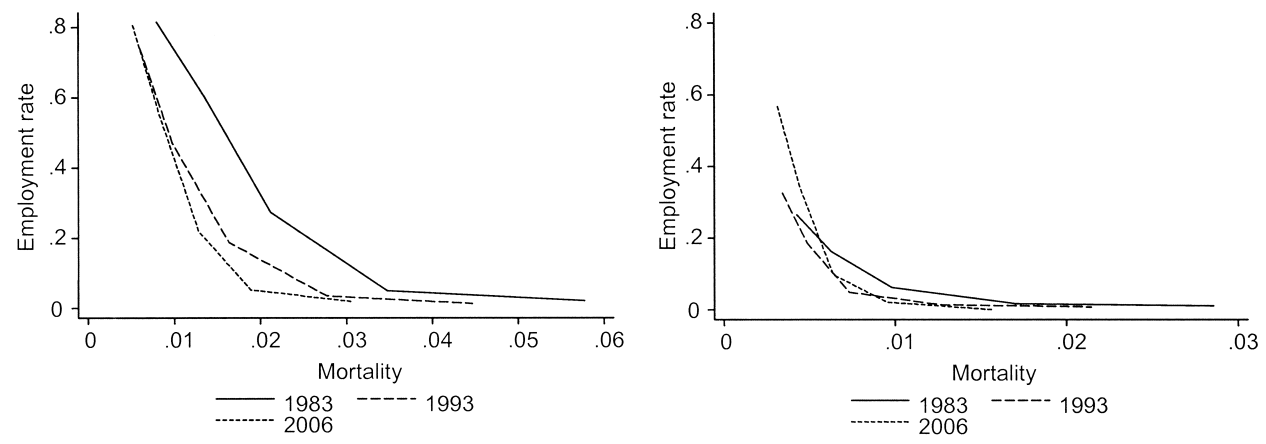

Fig. 6.11 Employment rate and mortality rate for male (left) and female (right)

Source: Labor Force Survey and Human Mortality Database.

is that as time went by, any given mortality level corresponded to a higher and higher age, which, in turns, is associated with a lower employment rate. For women, beyond this reduced mortality effect, there is a second strong generational factor at work, involving a steeply increasing labor force participation over the observation period.

\subsubsection{Social Security Program Participation}

\section{Disability Insurance}

While the preceding Labor Force Survey data have the distinct advantage of giving a close reflection of the individuals' true economic status, they are not able to reflect the richness of the Belgian institutional landscape. Therefore, it should not have come as a surprise that the aggregate data of the previous subsection do not seem to reflect any of the specific social security reforms we discussed in section 6.2. 
In order to investigate the effect of institutions on labor market participation, we draw on additional administrative data. In this context, program participation or "take-up" is defined as the number of individuals receiving benefits within the context of each program divided by the population in the corresponding cohort. To identify the various reforms to the social security schemes described in section 6.2, we draw vertical lines in the graphs plotting participation by age across time. These horizontal lines serve as a guide as to when the various reforms should have their effects or, at the very least, start having effects.

Looking at the DI program participation presented in figure 6.12, we observe different trends for male and female. Male DI rate for the age groups forty to forty-four, fifty to fifty-four, and fifty-five to fifty-nine is almost constant, while disability for those aged sixty to sixty-four is decreasing. None of the reforms to generosity and eligibility of DI seem to have had an impact on participation. However, reforms concerning access to other program may well explain part of the decrease - particularly for those aged sixty to sixtyfour. For example, this could have been the case with the opening up of the OAU route in 1985 and the introduction of a flexible age of retirement without actuarial adjustment factor in 1991. The positive trend for women of all age cohorts follows a different rationale mostly because of a strong expansion of the share of women in the labor market. While reforms to OAU and other early retirement routes affect women less due to insufficient work histories to qualify for such benefits, the increase of the female normal retirement age was not without effects such as previously discussed.

The Belgian disability administration prefers to use a different reference population when determining participation. Their reference population is composed of those individuals that are eligible to claim benefits because they contribute, minus those on CER because they do not have any economic incentives to switch to the DI system.
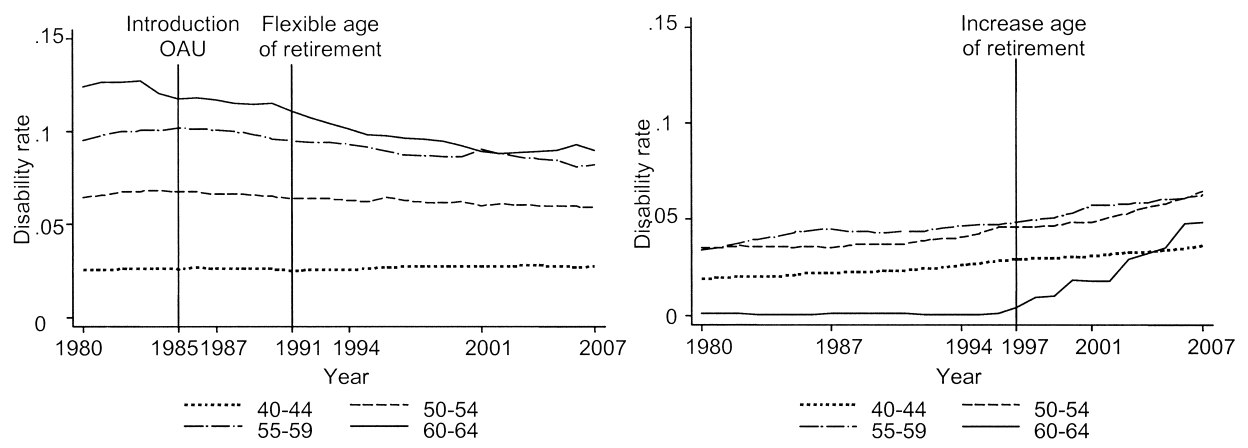

Fig. 6.12 DI participation for male (left) and female (right) Source: INAMI-RIZIV. 

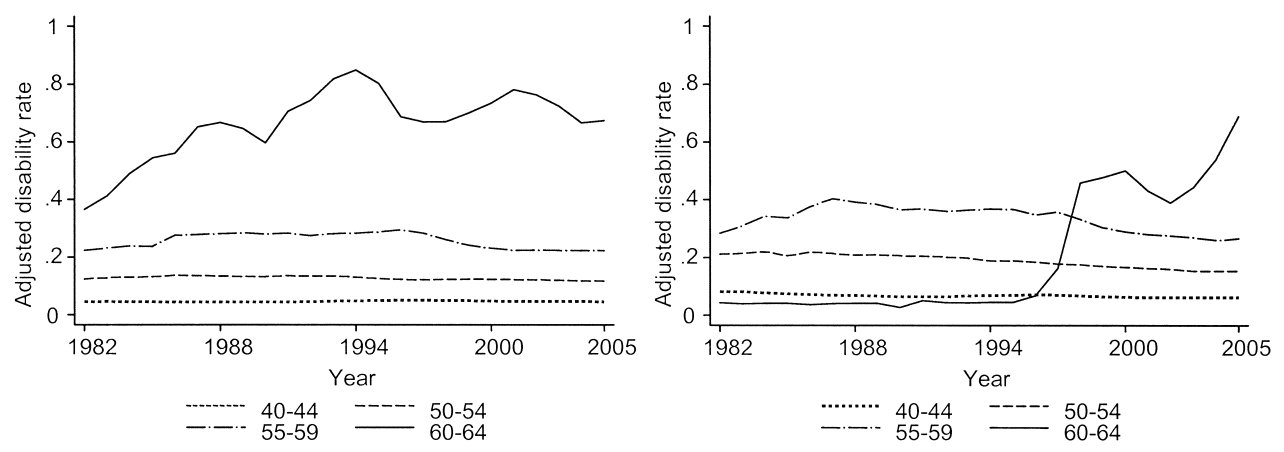

Fig. 6.13 Adjusted DI participation for male (left) and female (right) Sources: INAMI-RIZIV; ONEM; and BNB-Belgostat.

If one follows this logic of excluding those that are either not eligible or have no economic interest to join the DI ranks, then this definition of the population is still too broad. For example, it is highly likely that the individuals on UI and OAU also do not have much of an economic incentive to switch - given the previously discussed absence of explicit time limits in benefit receipt.

Using this adjusted population figure as a reference point, we derive equivalent participation trends over time (figure 6.13). The figures reveal much more sharply the effect of the reforms discussed in section 6.2. The increase in the age groups fifty-five to fifty-nine after 1986 corresponds to the introduction of the old-age unemployment status, which strongly reduces the denominator of the disability rate by shrinking the population that has an economic interest in claiming DI. Also, the initial trend observed for the age group sixty to sixty-four can be traced back to the increase in the number of retirees until 1987, thus shrinking the reference group. A similar logic applies to the early 1990s with its major reforms to the retirement system.

Summing up the information of figures 6.12 and 6.13, we can draw two conclusions. First, the trends in DI participation over time are not confined to the age group close to retirement, but also younger cohorts are affected. Second, while aggregate DI participation rates have stayed unchanged, there have been substantial changes to the people "at economic risk" of filing for DI benefits, notably because of reforms to the eligibility and generosity of other social security programs targeted at the older segments of the labor force.

\section{Other Social Security Programs}

The effect of other program is, however, not limited to the one of restricting the population economically at risk of filing for benefits. Indeed, the multiplicity and generosity of other exit routes make it possible that truly 
disabled people file for other social security benefits such as CER, OAU, or UI in lieu of filing for DI. In this sense, the question of evaluating the participation and the changes in participation over time is of prime importance.

We first focus on the regular UI program. As with the just discussed DI data, the UI data comes from the federal UI administration. The number of unemployed thus corresponds to the number of individuals currently claiming UI benefits under the rules in place. Given the institutional setup, this means that some truly unemployed people may not be eligible for benefits, while some segments of those receiving benefits would not be considered unemployed according to the standard definition of the International Labor Organization (ILO).

The time pattern of UI participation of figure 6.14 displays three clearly separated phases over time. Contrary to DI numbers, these rates seem to be independent of the demographic trend and are more heavily exposed to cyclical variations in the economy. Economic cycles don't, however, provide a complete picture.

The stark decrease of UI participation after 1984 can be traced back to the introduction of OAU such as identified by the first vertical line. The shift into OAU is, however, not total, if only because some people don't satisfy the somewhat more stringent entry criteria for the OAU system as compared to UI. Similarly, the further liberalization and expansion of the system in 1995 corresponds to the next drop of people on the UI rolls - an effect further reinforced by the arrival of the Canada Dry pensions in 1997. Finally, the third phase corresponds to the tightening of the access to OAU in 2002 - with an ensuing communicating vessels effect increasing UI as OAU decreases (see also figure 6.15).

However, the decrease in the number of unemployed is lower than the increase in the number of old-age unemployed - as a quick glance at the rates presented in figures 6.14 and 6.15 document. Thus, OAU clearly ap-
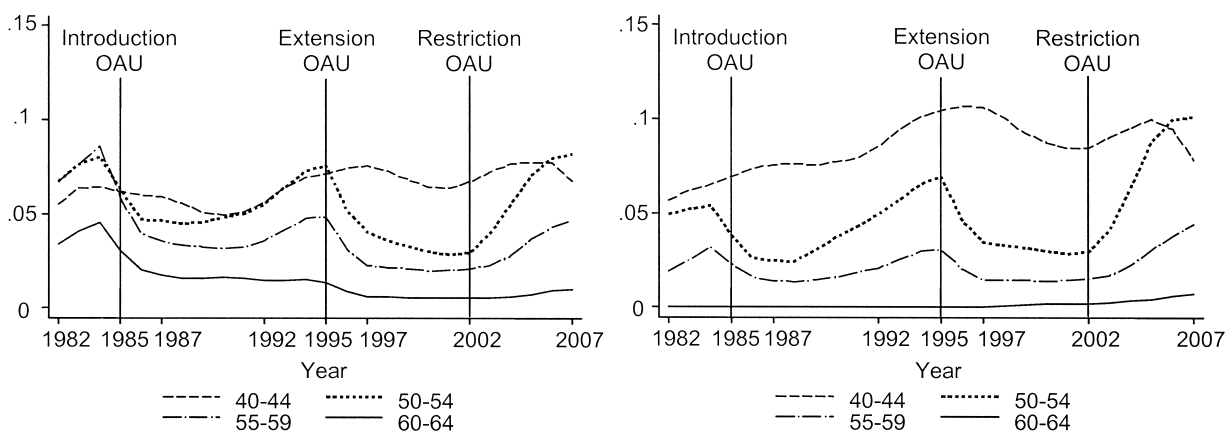

Fig. 6.14 UI participation for male (left) and female (right)

Source: BNB-Belgostat. 

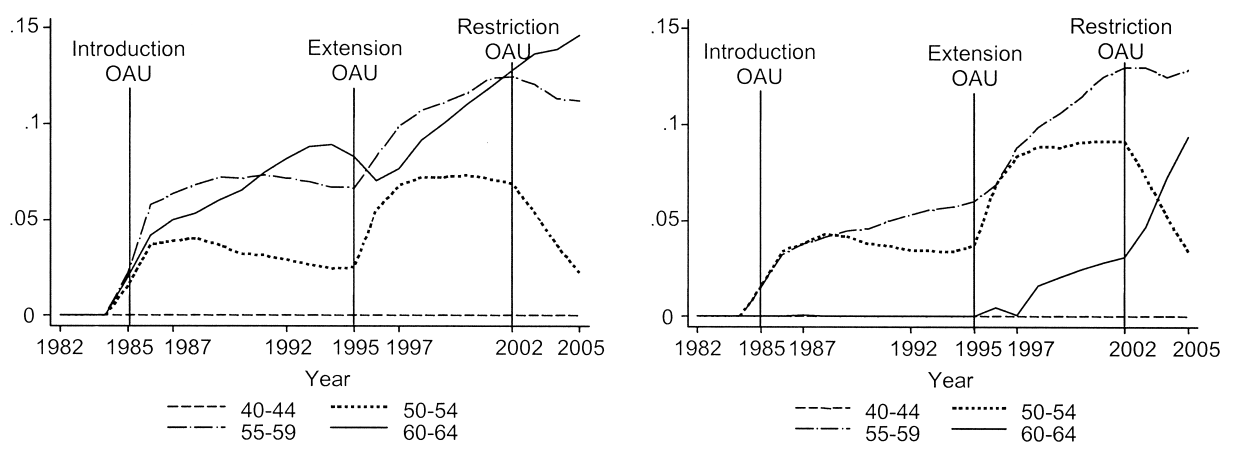

Fig. 6.15 OAU participation for male (left) and female (right) Source: ONEM-RVA.

pears as a new exit path with a net addition of exits and not only reallocations between programs.

As compared to their male counterparts, the situation for women is not very different, as the preceding figures 6.14 and 6.15 clearly illustrate. Unsurprisingly, the pattern for the sixty to sixty-four age group displays a somewhat different pattern than for men, again for the same reason as before: the initially lower retirement and early retirement ages for women, with the ensuing labor market effects after their progressive increase starting in 1997.

Finally, figures 6.16 and 6.17 present the trends regarding CER and the regular pension system participation. The CER trends for men of all age groups are characterized by a strong responsiveness to changes in the CER and OAU eligibility affecting the relative attractiveness of this system. Women benefit much less from the system, given the career length requirements that are often a nontrivial hurdle in case of incomplete careers. The two reforms to the main pension system modifying the early and normal retirement ages for women have the expected effects on CER and the pension scheme - with shifts toward CER in the affected groups.

For men, the trends in the regular pension system reflect reforms rather closely until the end of the last millennium. For example, the increase for ages sixty to sixty-four over the first half of the 1980s is related to the SER and RPP measures. The observed path after 2000 cannot be traced back to any specific legislative change and coincides with general improvements on the labor market leading to an increase in the effective age of retirement. Similarly, the trends for the female age group sixty to sixty-four before the progressive increase of the retirement age as of 1997 is difficult to link to any specific change: the participation rates being stocks, they reflect the cumulative weight of past reforms. Thus, changes to the OAU, the UI, and the CER have no doubt had an influence. However, they are insufficient to explain the sheer size of fluctuations observed in the pension scheme that might partially 

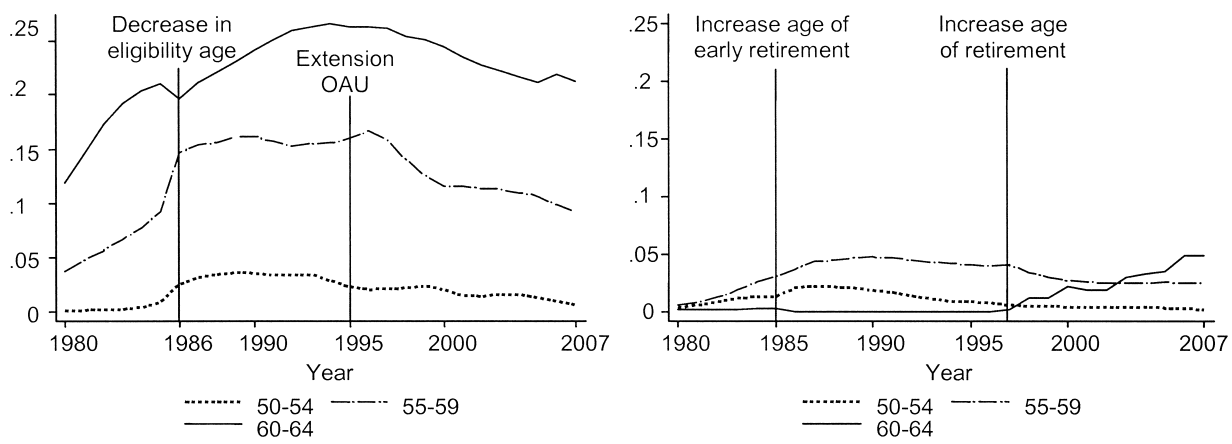

Fig. 6.16 CER participation for male (left) and female (right)

Source: INAMI-RIZIV.
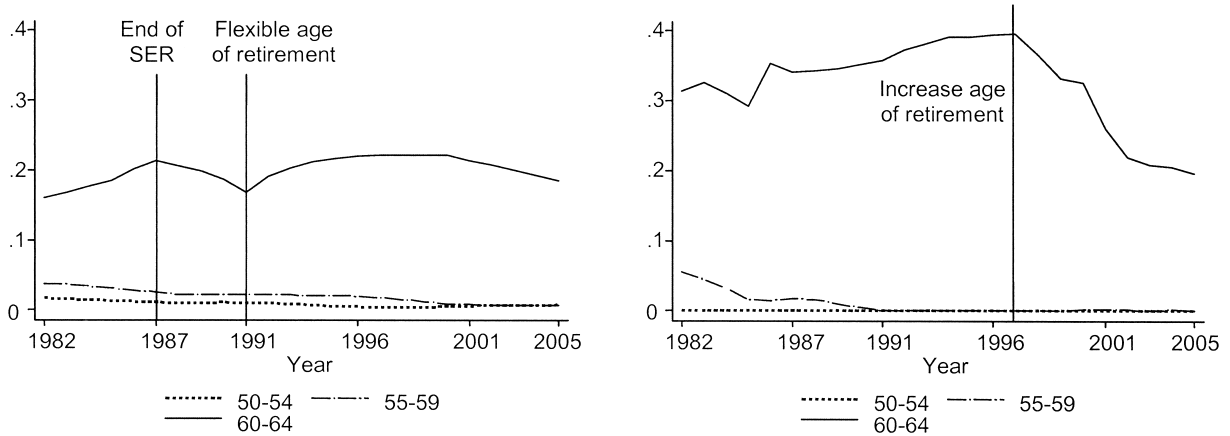

Fig. 6.17 Retirement participation for male (left) and female (right)

Source: ONP-RVP.

also be due to interactions of incentives and benefits for couples as well as the sometimes unpredictable effect of incomplete careers on benefit eligibility.

Figure 6.18 presents the information on program participation in a synthetic way for all available social security systems. Figure 6.18 highlights the connected vessels aspect of the various social security schemes with a strong role for OAU. Also, by now, OAU and UI combined account for more than 35 percent of all workers in the fifty to sixty-four age bracket making the unemployment benefit receipt the single most prominent retirement status. The fraction even rises to well beyond 60 percent when integrating the CER schemes that are also administered through the UI scheme.

\subsubsection{Mortality, Health, and DI}

Figure 6.19 displays the overall enrollment or participation in the different systems on a year-by-year basis. The results show the relative constancy of 


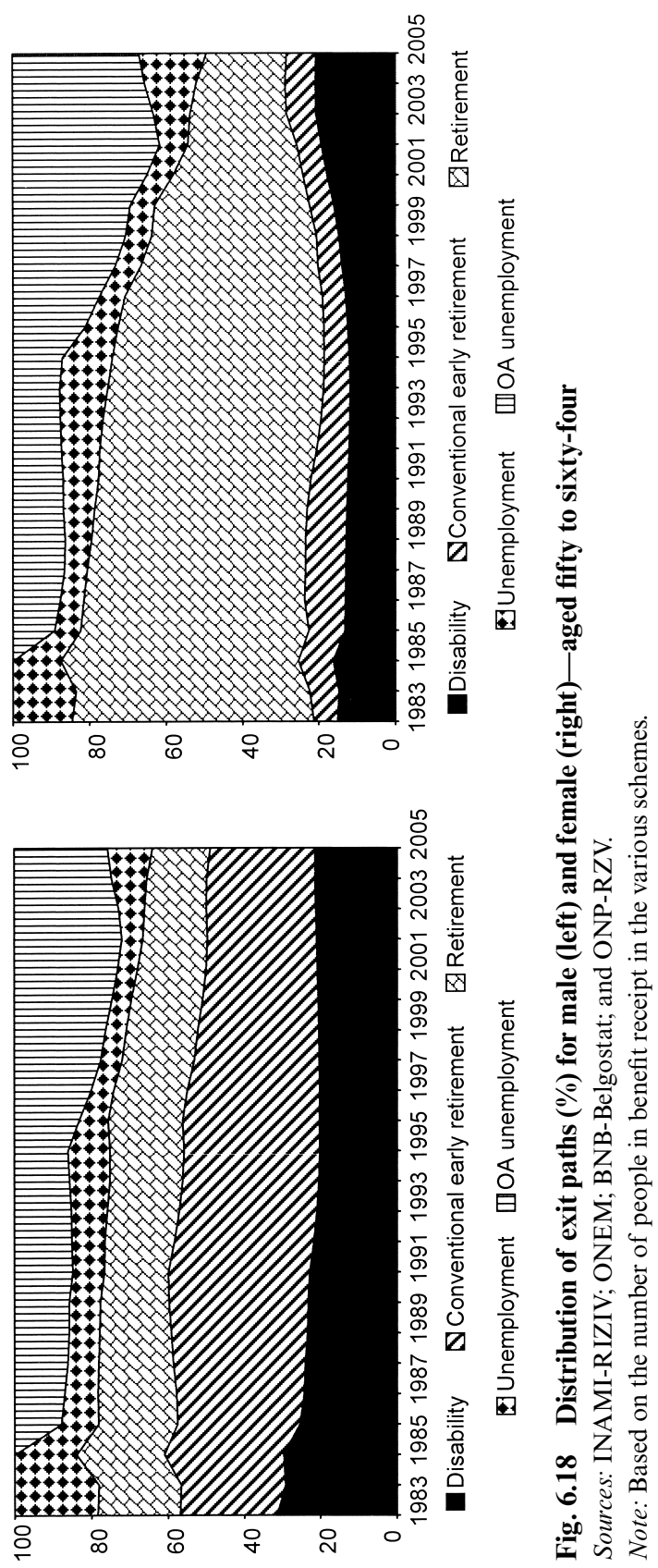




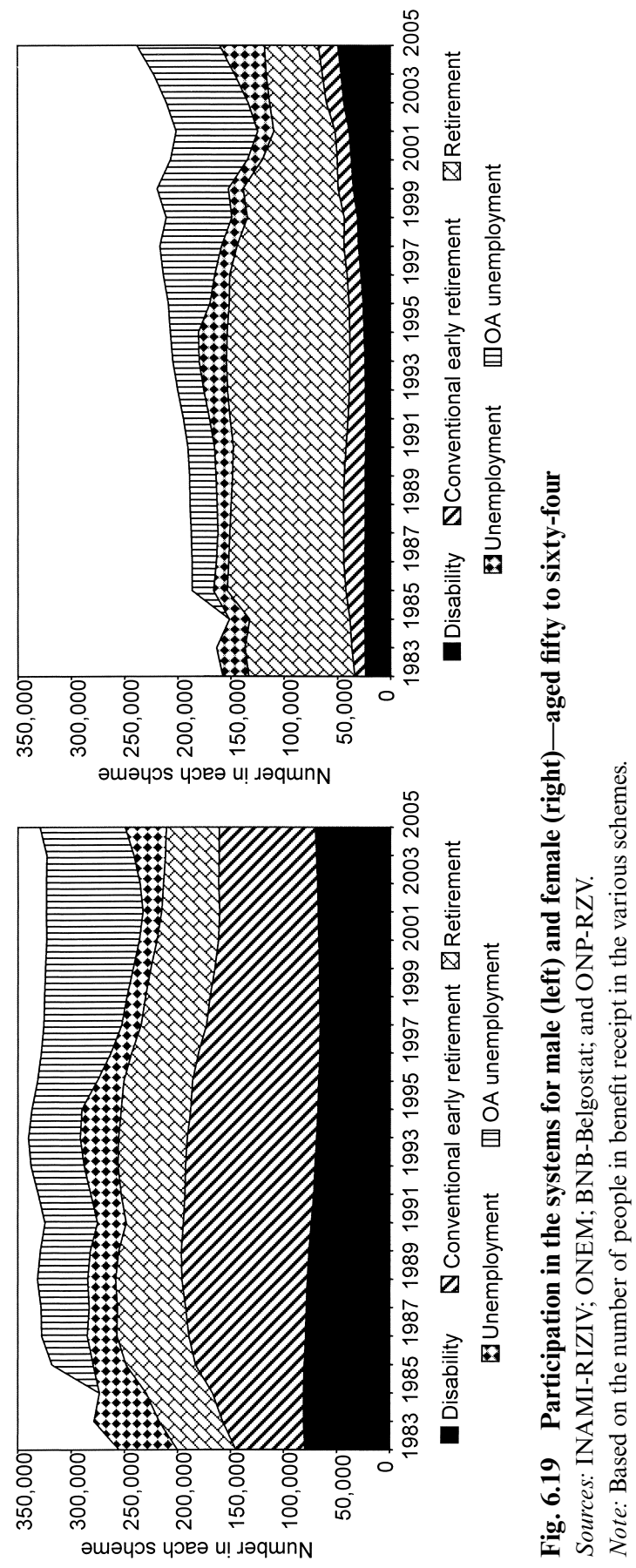


the DI scheme-with enrollment rather stable for males and growing progressively for females. Two interpretations are possible. First, the optimistic one would argue that entry into the DI program is so severely limited by powerful and effective gatekeeping mechanisms making it close to impossible to enter the system unless a serious medical or psychological condition exists. In this vein, stability is the result of good management, and the growth of the female participation is attributed to the increase in the normal retirement age, which mechanically increases the number of DI beneficiaries. The second and less optimistic interpretation is that other social insurance programs are sufficiently generous in terms of access and benefit levels, thereby rendering the more stringent DI system less attractive.

The data of figure 6.20 raise further doubts with respect to a contemplative view of DI as a severely controlled and rather steady system. When decomposing by primary cause of DI benefit payment, one notices that mental health issues become a more and more prevalent issue as compared to purely physical ones. This leads to interesting avenues for future research: could DI payments be lower if more severely tested? Do other programs also have a changing pool of beneficiaries, maybe including increasing numbers of truly disabled people?

This idea is further reinforced when looking at the relative prevalence of DI participation in the populations aged forty to forty-four and sixty to sixty-four, the former not being eligible for other early retirement programs. These data are represented in figure 6.21 and show steep decline in the difference between the two groups - hence indicating a relatively lower prevalence of DI cases in the older population as time went by. Though these data don't allow us to conclude formally on the shifting of true DI recipients onto other programs, such a phenomenon is highly likely.

\subsection{Conclusions}

Disability insurance has attracted a limited interest in the Belgian policy debate. This is no doubt influenced by the relatively limited budgetary cost of this program, when comparing it to its bigger health and public pension siblings.

The present chapter shows that disability insurance indeed seems to have a rather unspectacular time trend over the last decades. We show that the other social security programs allowing an early exit from the labor market play the key role in the Belgian retirement context.

As compared to younger cohorts, older workers tend to benefit from disability payments less and less frequently. Furthermore, the composition of the disabled population is changing over time, with increasing numbers of benefits being based on mental problems that are intrinsically harder to check than physical impairments.

This has two policy implications. First, in spite of its appearance, the 


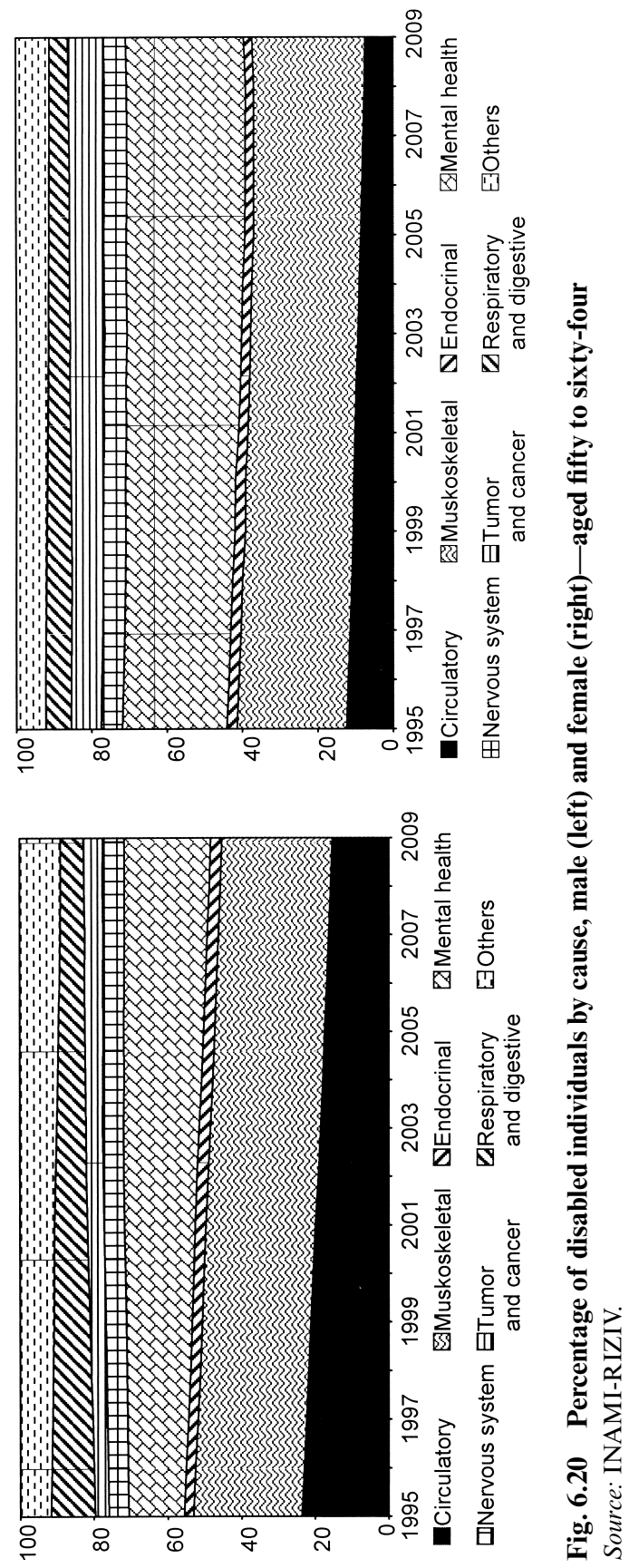






Fig. 6.21 DI participation aged sixty to sixty-four less aged forty to forty-four for men

Source: INAMI-RIZIV.

increasing role of harder-to-check benefit decisions may well mean that the disability program is serving as an early retirement route. Second, substantial numbers of disabled may, in fact, be using other social security programs to exit the labor market. The latter would mean that the various social insurance programs are getting more and more diverted from their original aims - in the Belgian context, particularly the unemployment system.

Additional research on the underlying health characteristics of the beneficiaries of the various social security programs would be warranted to guide any future reforms. A further area of investigation could be a systematic analysis of the work environment that people face during their active life. This environment has no doubt undergone profound changes over the last decades, both because of a seminal trend toward the service sector and stricter general work-safety requirements in place.

\section{References}

Cremer, H., J. M. Lozachmeur, and P. Pestieau. 2009. "Use and Misuse of Unemployment Benefits for Early Retirement." European Journal of Political Economy 27 (2): $174-85$.

Dellis, A., R. Desmet, A. Jousten, and S. Perelman. 2004. "Micro-Modelling of Retirement in Belgium." In Social Security and Retirement Around the World: Micro-Estimation, edited by J. Gruber and D. Wise, 41-98. Chicago: University Chicago Press.

Desmet, R., A. Jousten, S. Perelman, and P. Pestieau. 2007. "Micro-Simulation of Social Security in Belgium.” In Social Security Programs and Retirement Around 
the World: Fiscal Implications of Reform, edited by J. Gruber and D. Wise, 43-82. Chicago: University Chicago Press.

Disney, R., C. Emmerson, and M. Wakefield. 2006. "Ill Health and Retirement in Britain: A Panel Data-Based Analysis." Journal of Health Economics 25 (4): 621-49.

Faniel, J. 2008. "Unemployment Insurance between European Pressures and Regional Polemics." Chroniques internationales de l'IRES 115 (November): 52-64.

Jousten, A., M. Lefebvre, S. Perelman, and P. Pestieau. 2005. "Social Security in Belgium: Distributive Outcomes." IZA Discussion Paper no. 1486. Bonn, Germany: Institute for the Study of Labor.

- 2010. "The Effect of Early Retirement on Youth Unemployment: The Case of Belgium." In Social Security Programs and Retirement Around the World: The Relationship to Youth Employment, edited by J. Gruber and D. Wise, 47-76. Chicago: University Chicago Press.

Kalwij, A., and F. Vermeulen. 2008. "Health and Labour Force Participation of Older People in Europe: What Do Objective Health Indicators Add to the Analysis." Health Economics 17 (5): 619-38.

Pestieau, P., and J. P. Stijns. 1999. "Social Security and Retirement in Belgium." In Social Security Programs and Retirement Around the World, edited by J. Gruber and D. Wise, 37-71. Chicago: University Chicago Press.

Walker, T. 2007. "Why Economists Dislike a Lump of Labor." Review of Social Economy 65 (3): 279-91. 